\title{
Synthesis and Mechanical Characterization of Grewia Serrulata Short Natural Fiber Composites
}

\author{
Mahesh G T $\mathrm{T}^{\dot{\mathrm{A}}^{*}}$, Satish Shenoy $\mathrm{B}^{\dot{\mathrm{A}}}$, Padmaraj $\mathrm{N} \mathrm{H}^{\dot{\mathrm{A}}}$ and Chethan $\mathrm{K} \mathrm{N}^{\dot{\mathrm{A}}}$ \\ ${ }^{\grave{A}}$ Dept of Automobile Engineering, Manipal Institute of Technology Manipal, Karanataka, India-576104 \\ Accepted 9 January 2014, Available online 01 February 2014, Special Issue-2, (February 2014)
}

\begin{abstract}
Composite materials based on Grewia Serrulata as reinforcing fibers and polyester resin were prepared by hand lay-up technique and characterized, in terms of mechanical performance. Optimizing the length of the fibers for adequate mechanical properties is attempted in the present work. The mechanical properties of the composites were improved by reinforcing with short fibers. These scarcely cited fibers in the contemporary research work assure confidence for the further enhancement in their usage for various applications with continued research. The low density of the fibers results in light weight composites so that the overall weight of the system could be reduced considerably.
\end{abstract}

Keywords: Grewia Serrulata, Natural fiber, Tensile Strength, Flexural Strength, Composite

\section{Introduction}

Rapidly depleting fossil fuel sources have triggered the urgent need for the development of alternative and nature friendly materials such as natural fiber composites. Currently, synthetic fibers like glass, carbon and aramid are widely being used in polymer-based composites because of their high stiffness and strength properties. However, these fibers have serious drawbacks in terms of their lack of biodegradability, higher initial processing costs, recyclability, energy consumption, machine abrasion, health hazards, etc. (Rout et al, 2001), (Bledzki et al, 1999). As an alternative to these synthetic materials, the use of natural fibers in making newer materials for variety of applications is gaining popularity. Some of the proven fields of applications for such materials are automotive, packaging, furniture and interiors. This is because of multiple advantages associated such as bio degradability, lightweight materials, non-allergic nature, less reliance on rapidly depleting petroleum resources etc. (Abdelmouleh et al, 2007), (Tserki et al, 2005). In this context, any new or alternative method that reduces the burden on the expensive fuels is a well come effort.

A bast fiber from the plant Grewia Serrulata which has not been found used in making the materials is tried in the present work as the reinforcement. It is presumed that by utilizing such fibers for the composites, value addition can be done for such plant products. Traditionally Grewia Serrulata fibers have been used by local people for making ropes, knots, bags, threads, baskets etc. But presently, we have used these fibers as reinforcement in composite materials. It generally contains cellulose, hemicelluloses and lignin in the ranges of $58-62 \% ; 20-25 \%$ and $15-20 \%$ respectively.

In the current study, polymer matrix composites, with Grewia Serrulata as reinforcement and polyester as the resin, are prepared and characterized. The density of the fibers used in the study is estimated as $1.1 \mathrm{~g} / \mathrm{cc}$ and that of the polyester resin is $1.02 \mathrm{~g} / \mathrm{cc}$.

Some of the researches carried out by using natural fibers as reinforcements is taken as a basis for the present work. These are summarized below.

(Hamdan et al, 2008) carried out study on the effect of alkaline treatment on tensile properties of sugar palm fiber reinforced epoxy composite. The sugar palm epoxy composite plate was fabricated on one type volume fraction i.e. $10 \%$. The laminated composite plate was produced by hand lay-up process and was cut to form a specimen test based on ASTM D638-99.

(Mulinari et al, 2011) studied mechanical properties of coconut fibers Reinforced Polyester Composites. Coconut fibers were extracted and dried at $80^{\circ} \mathrm{C}$ for $24 \mathrm{~h}$. Polyester was used as a resin along with treated coconut fiber. Composite was manufactured by compression moulding technique. Mechanical tests were carried through in a servo-hydraulic MTS model $810.23 \mathrm{M}$. The dimensions were according to ASTM standards D3039.

(Hung et al, 2008) conducted a study on tensile behaviors of the coir fiber and related composites after alkali treatment. Coconut fibers were obtained from retting process. Coir fibers were treated in the $\mathrm{NaOH}$ solutions at the room temperature $\left(26-28{ }^{\circ} \mathrm{C}\right)$ with densities of $2 \%$, $4 \%, 6 \%, 8 \%$ and $10 \%$, respectively. Alkali treated and untreated were cured in an oven, and then conditioned under the environment of relative humidity of $65 \%$ and 
temperature at $20^{\circ} \mathrm{C}$ for $24 \mathrm{~h}$ before the tensile strength test.

(Rajulu et al, 2005) reinforced short natural fiber belonging to the species Hildegardia Populifolia in styrenated polyester matrix. The mechanical properties of the composites reinforced with alkali treated fibers were determined and compared with untreated fibers. Tensile modulus is measured using Instron UTM model: 1175 (UK).Alkali treatment of the fibers enhanced the tensile modulus by $3.5 \%$ and compressive strength by $7.5 \%$.

(Shinji et al, 2008) studied the mechanical properties of kenaf fibers. Kenaf fiber with a diameter of 50-150 micrometer and length of $500 \mathrm{~mm}$ were used. An emulsion-type poly-lactic acid resin was used as the matrix. Tensile tests and three-point flexural tests were conducted. Tensile tests were performed at a strain rate of 0.02 per min and a gauge length of $50 \mathrm{~mm}$. Unidirectional biodegradable composites fabricated using an emulsiontype poly-lactic acid resin and kenaf fibers at a fiber content of $70 \%$ have high tensile and flexural strengths of $223 \mathrm{MPa}$ and $254 \mathrm{MPa}$, respectively.

The literature review reveals that natural fibers can be reinforced with suitable polymers and can be used for light load carrying and in automotive interior applications. In this paper authors studied the mechanical properties of Grewia Serrulata fibers reinforced with polyester resins.

\section{Preparation of composites}

The fibres selected for the preparation of the composites were extracted from Grewia Serrulata plant which belongs to Tiliaceae family, locally known as Gurguri.

The stems from the plant were collected and immersed in water for four days. After soaking fibres were extracted from the stem by using metal wire brush without damaging them. The fibre strands which were originally in lumps were split manually and made into single strands. The fibres were split into single strands without damaging the fibre surface. Then they were cut into sizes of $10 \mathrm{~mm}$, $20 \mathrm{~mm}$ and $30 \mathrm{~mm}$. The fibres were dried in room temperature for 48 hours to reduce the moisture content.

Hand lay-up technique is used for the fabrication of the natural fibre - polyester composites. The specimens were prepared in a mould having dimensions $30 \times 15 \times 0.5 \mathrm{~cm}$. Specimens were prepared with $10 \mathrm{~mm}, 20 \mathrm{~mm}$ and $30 \mathrm{~mm}$ length of fibres keeping volume fraction of fibres as $15 \%$. The prepared specimens were allowed to cure in room temperature for 36 hours. Figure 1 and 2 shows the mould used to prepare the specimen and Grewia Serrulata fibre reinforced composite material respectively.

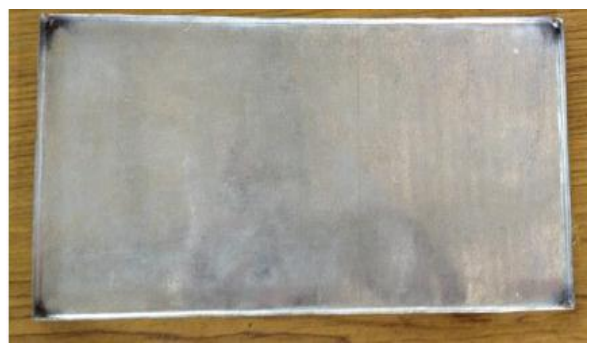

Fig.1 Mould for specimen preparation

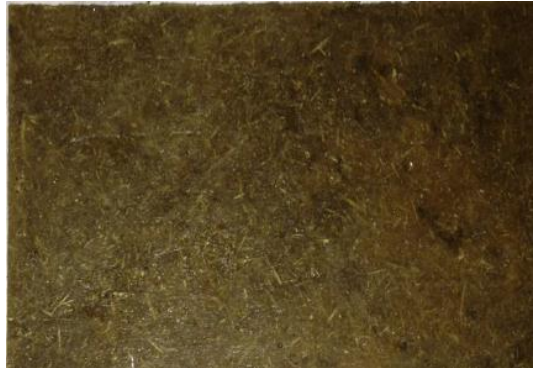

Fig.2 Grewia Serrulata reinforced composite

\section{Mechanical Properties Investigation}

The specimens of Grewia Serrulata natural fibre reinforced with polyester resin tested for mechanical properties such as tensile strength, flexural strength and wear test according to ASTM standards. Tensile test of specimens carried out according to ASTM D 3039 at a feed rate $0.5 \mathrm{~mm} / \mathrm{min}$ in universal testing machine Instron 3366 Figure 3 shows the specimen used to prepare the composite material.

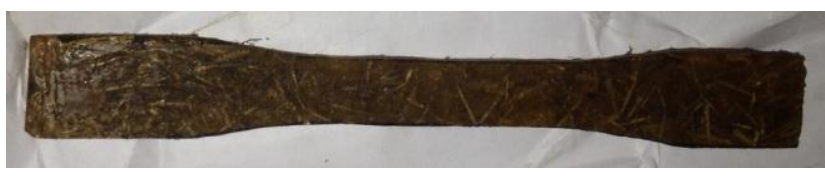

Fig.3 Specimen for Tensile Strength

Three point flexural strength of the Grewia Serrulata fibre reinforced composite materials was investigated according to ASTM D 790. Figure 4 shows the specimen used to conduct flexural strength test.

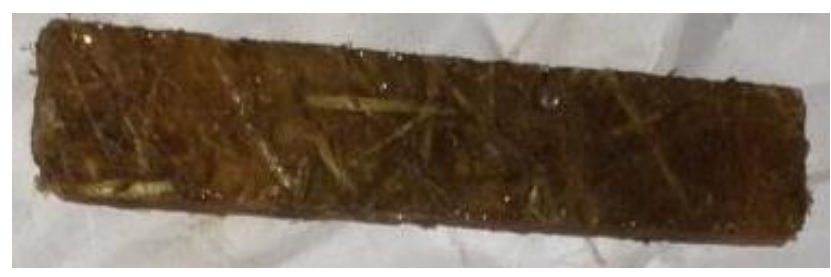

Fig.4 Specimen for flexural strength test

Wear can be considered as erosion from its derivative and original position on a solid surface performed by the action of the surface. It can also be defined as a process where interaction between two surfaces and bounding faces solids within the working environment results in dimensional loss of one solid with or without loss of material.

Pin on disk wear test rig is used for the study of wear pattern of the test specimens. In this test a pin slides on a horizontally- oriented rotating disk. Sliding speed is controlled by rotational speed and sliding path diameter. Contact pressures are controlled by applied load and pin diameter. A stationary block specimen is pressed with a constant force against a rotating ring specimen at $90^{\circ}$ to the ring's axis of rotation. Friction between the sliding surfaces of the block and ring results in loss of material from both pieces. Figure 5 shows the setup used to 
determine the tensile strength, flexural strength and wear rate of different length fibre reinforced composite material.
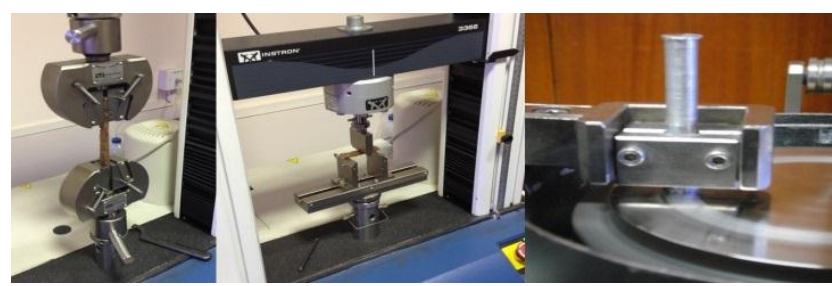

Fig.5 Tensile, Flexural and Wear test setup

\section{Result and discussions}

In the present study tensile test on $10 \mathrm{~mm}, 20 \mathrm{~mm}$ and $30 \mathrm{~mm}$ length Grewia Serrulata natural fiber composites was carried out. Figure 6 shows the load vs extension curve of tensile test. From the figure it is clear that as the length of fibers decreased it leads to improvement in the tensile strength. The increase in tensile strength with short fiber reinforcement is due to enhanced load transfer between matrix and fiber interface. However composite showed a decline in tensile strength beyond optimum fiber length of $10 \mathrm{~mm}$ due to agglomeration of fibers.
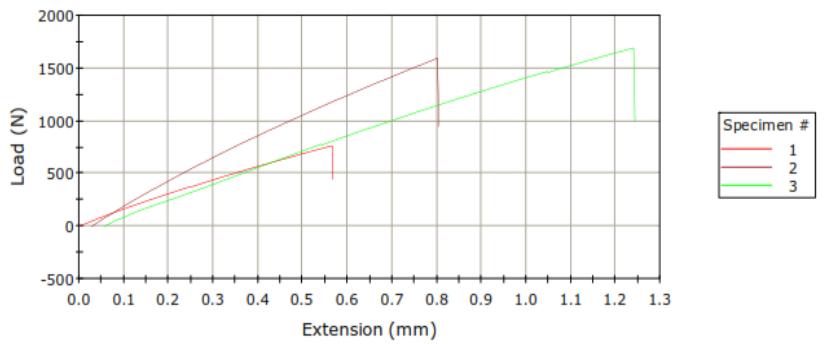

Fig.6 Load vs Extension curve of tensile strength

Table 1 show the maximum load applied on the specimen before breaking point.

Table.1Tensile test results of specimen

\begin{tabular}{|l|l|l|l|}
\hline Specimen & $\begin{array}{l}\text { Maximum Load } \\
\text { in N }\end{array}$ & $\begin{array}{l}\text { Tensile strength at } \\
\text { maximum load (MPa) }\end{array}$ & $\begin{array}{l}\text { Modulus } \\
(\mathrm{MPa})\end{array}$ \\
\hline 1 & 763.635 & 10.909 & 2084.162 \\
\hline 2 & 1592.48 & 22.749 & 3255.12 \\
\hline 3 & 1690.46 & 24.149 & 2040.57 \\
\hline
\end{tabular}

Flexural strength test of specimens shows that the specimens prepared with $20 \mathrm{~mm}$ length fiber composites could bear higher load than the other specimens. Table 2 shows the values of maximum flexural stress and strain for the different length of fiber reinforcements. Figure 7 shows the plot of flexural stress vs flexural strain.

Table.2 Results of flexural strength test

\begin{tabular}{|l|l|l|}
\hline Specimen & $\begin{array}{l}\text { Flexural load at maximum } \\
\text { stress(N) }\end{array}$ & $\begin{array}{l}\text { Maximum flexural } \\
\text { stress }(\mathrm{MPa})\end{array}$ \\
\hline 1 & 32.38 & 5.60 \\
\hline 2 & 261.59 & 45.20 \\
\hline 3 & 121.53 & 21.00 \\
\hline
\end{tabular}

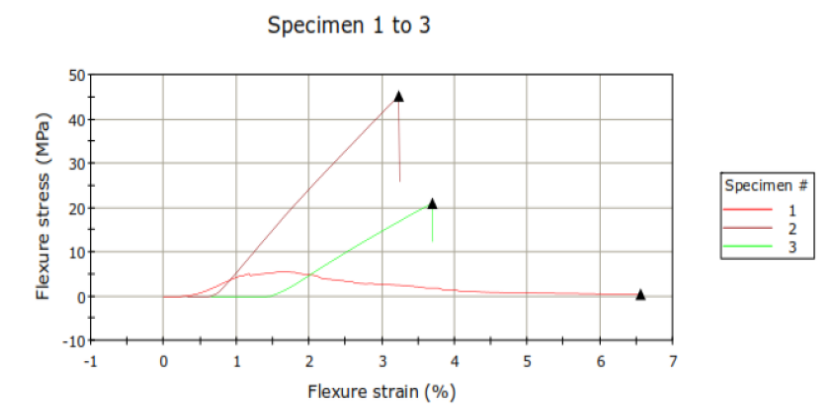

Fig.7 Plot of Flexural stress vs flexural strain

It is found from the results of the wear test that short reinforcement fibers in the composite showed least wear characteristics at all rotational speeds of the disc. Also, in general as the relative speed between the disc and the composite increases the wear rate increases as well. Maximum wear rate was observed with $20 \mathrm{~mm}$ length reinforced fibers while $10 \mathrm{~mm}$ length fibers offered least wear at all speeds of rotation of the disc. This is probably due to proper mixing and wetting of the fibers in the mixture. The wear rate of specimens with 10, 20 and 30 $\mathrm{mm}$ length reinforcing fibers is shown in table 3 .

Table 3: Results of wear test

\begin{tabular}{|c|c|c|c|c|c|c|c|}
\hline \multirow{3}{*}{$\begin{array}{c}\text { Fibre length } \\
\text { in Specimen }\end{array}$} & $\begin{array}{c}\text { Speed } \\
\text { (RPM) }\end{array}$ & $\begin{array}{c}\text { Weight } \\
\text { before } \\
\text { wear in } \\
\text { grams }\end{array}$ & $\begin{array}{c}\text { Weight } \\
\text { after wear } \\
\text { in grams }\end{array}$ & $\begin{array}{c}\text { Difference } \\
\text { in gram }\end{array}$ & $\begin{array}{c}\text { Volume } \\
\text { removed in } \\
\text { mm }^{3}\end{array}$ & $\begin{array}{c}\text { Sliding } \\
\text { distance in } \\
\text { mm }\end{array}$ & $\begin{array}{c}\text { Wear rate } \\
\text { mm }\end{array}$ \\
\hline \multirow{5}{*}{$10 \mathrm{~mm}$}
\end{tabular}

\section{Conclusions}

1) Grewia Serrulata plant fibres can be successfully used as reinforcements in the preparation of composite materials.

2) Tensile strength of the composites with a fibre length of $10 \mathrm{~mm}$ is higher than for composites with longer fibres as reinforcement.

3) Flexural strength of composites with $20 \mathrm{~mm}$ length fibres is optimum, thus too short or too longer fibres as reinforcement offers lower bending properties.

4) The $10 \mathrm{~mm}$ fibre length composite has the least wear rate, thus short fibre composites can be used in applications such as in making the parts with slight relative motion between them. 


\section{References}

Rout J, Misra M, Tripathy S, Nayak SK, Mohanty A K, (2001), The influence of fiber treatment on the performance of coirpolyester composites, Composite Science Technology; 61(9):1303-10.

Bledzki AK, Gassan J, (1999), Composites reinforced with cellulose based fibers, Polymer Science, 24(2):221-74.

Abdelmouleh M, Boufis S, Belgacem MN, Dufresne, (2007), Short natural-fibre reinforced polyethylene and natural rubber composites: effect of silane coupling agents and fibre loading, Composite Science Technoogyl 2007, 67 (7-8):1627-39.

Tserki V, Zafeiropoulos NE, Simon F, Panayiotou C, (2005), A study of the effect of acetylation and propionylation surface treatments on natural fibres, Composites Part A - Applied Science Manufacturing 2005, 36(8):1110-8.
M.M. Hamdan D, Bachtiar, S.M. Sapuan, M.M. Hamdan, (2008), The effect of alkaline treatment on tensile properties of sugar palm fiber reinforced epoxy composites, Materials and Design 28 November 2007 1285-1290.

Mulinari, D.R. Baptista, Souza, J. V. C.,Voorwald, H.J.C, (2011), Mechanical Properties of Coconut Fibers Reinforced Polyester, Procedia Engineering 10 2074-2079

Huang $\mathrm{Gu}$, (2008), Tensile behaviours of some high performance filaments after $\mathrm{NaOH}$ treatment, Materials and Design 29 1893-1896

Varada Rajulu A, Babu Rao G and Ganga Devi L, (2005), Mechanical Properties of Short, Natural Fiber Hildegardia populifolia-reinforced Styrenated Polyester Composites, Journal of Reinforced Plastics and Composites, Vol. 24, No. 4 Shinji Ochi,(2008), Mechanical properties of kenaf fibers and kenaf/PLA composites, Mechanics of Materials 40 446-452 